XXVII. Balkan Clinical Laboratory Federation Meeting BCLF 2019

XXX. National Congress of the Turkish Biochemical Society TBS 2019

\title{
BCLF WELCOME LETTER
}

Dear friends and colleagues,

On behalf of Balkan Clinical Laboratory Federation it is my great pleasure to invite you to take part on this great scientific event to be held on 27-31 October 2019 in Antalya - Turkey.

Gear up for an exciting and informative $27^{\text {th }}$ Balkan Clinical Laboratory Federation Meeting that will enable You to refresh your knowledge base, explore innovations, exchange ideas, meet other researches, friends and colleagues as well as sponsors and exibitors.

The Meeting will cover all the scientific and technological aspects of Laboratory Medicine. Ideal location to participate to very advanced scientific presentations combined with well balanced programme of oral and poster presentations, and dedicated workshops, will guarantee an efficient exchange of ideas and allow productive discussions.

These are exciting times in the world of laboratory medicine and I am sure that $27^{\text {th }}$ BCLF Meeting will be a rewarding and unforgettable experience for all participants.

I look forward to meeting you all in beautiful Turkey.

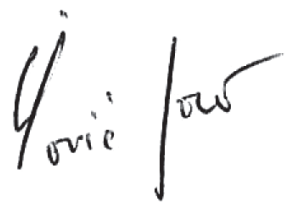

Jozo Coric

BCLF President 